\title{
Особенности тактики многоэтапного хирургического лечения открытых переломов
}

\author{
Н. Л. Анкин ${ }^{1,2}$, Т. М. Петрык ${ }^{1}$, В. А. Ладыка ${ }^{2}$ \\ ${ }^{1}$ Киевская областная клиническая больница, \\ ${ }^{2}$ Национальная медицинская академия последипломного образования имени П. Л. Шупика, г. Киев

\section{Peculiarities of tactics in multistage surgical treatment of open fractures}

\author{
M. L. Ankin ${ }^{1,2}$, T. M. Petryk ${ }^{1}$, V. O. Ladyka ${ }^{2}$ \\ ${ }^{1}$ Kiev Regional Clinical Hospital, \\ ${ }^{2}$ Shupyk National Medical Academy of Postgraduate Education
}

\section{Реферат}

Цель. Изучить результаты применения классической тактики и тактики многоэтапного хирургического лечения открытых переломов (ОП), обсудить вопросы выбора метода фиксации ОП и возможности раннего закрытия обширных ран и дефектов мягких тканей.

Материалы и методы. Проанализированы результаты лечения 286 пациентов с ОП костей верхних и нижних конечностей в ортопедо-травматологическом центре Киевской областной клинической больницы за период с 2008 по 2016 г. Применяли классические методы и тактику многоэтапного хирургического лечения.

Результаты. Оценивали результаты хирургического лечения ОП костей верхних и нижних конечностей с использованием балльной шкалы Neer-Grantham-Shelton. Хорошие результаты получены у 54,84\% пациентов 1 -й группы и у 80,28\% пациентов 2-й группы.

Выводы. Успех лечения ОП зависит от ранней госпитализации, ранней радикальной хирургической обработки, стабильной фиксации сломанной кости, применения рациональных доз антибиотиков, коррекции иммунологического статуса. Одними из наиболее спорных и нерешенных остаются проблемы выбора метода фиксации ОП и раннего закрытия раны.

Ключевые слова: открытый перелом; открытый перелом костей голени; замена метода фиксации; аппарат внешней фиксации.

Abstract

Objective. Using comparison of application results of classic tactics vs tactics in multistage surgical treatment for OF, to discuss the issues of choice of the OF fixation method and possibilities of early closure of extensive wounds and defects of soft tissues. Materials and methods. Results of treatment for OF of the upper and lower extremities bones in Orthopedic-Traumatological Centre of Kiev Regional Clinical Hospital in 2008 - 2016 yrs period in 286 patients were analyzed. Classic methods and tactics of multistage surgical treatment were used.

Results. Results of surgical treatment of OF of the upper and lower extremities bones, using the Neer-Grantham-Shelton score scale, were estimated. Good results were obtained in $54.84 \%$ patients of Group I and in $80.28 \%$ patients of Group II.

Conclusion. Success of treatment of OF depends upon early admittance to hospital, early radical surgical processing performance, achievement of stable fixation of fractured bone, rational application of antibiotics, and correction of immunological status. The problems of choice of the OF fixation method and the early closure of the wound performance are the most unequivocal and unsolvable.

Keywords: open fracture; open fracture of the shin bones; change of the fixation method; apparatus of external fixation.

При любом ОП лечение направлено на обеспечение неосложненного заживления ран мягких тканей и самого перелома с целью восстановления нормальной функции конечности. Полное восстановление функции конечности возможно за счет ранних активных движений в ближайших к месту перелома суставах, но применяемые методы стабилизации ОП и закрытия обширных ран с дефектом мягких тканей часто не обеспечивают этого.

При ОП большеберцовой кости 3С степени по классификации Густильо-Андерсена даже в лучших лечебных учреждениях ампутацию производят более чем у 50\% больных [1]. После первичного внутрикостного или накостного остеосинтеза гнойные осложнения возникают у 18 - 24\%, после внешней фиксации - у 2 - 6,6\% больных [2-4]. Внешний остеосинтез является надежным миниинвазивным средством стабилизации, снижающим риск осложнений, однако спицы или стержни аппарата, проходящие через мышцы, препятствуют восстановлению первоначальной функции. Необходим поиск новых более эффективных тактик и методов лечения ОП.

Цель исследования: изучить путем сравнения результаты применения при ОП классической тактики и тактики многоэтапного хирургического лечения, обсудить вопросы выбора метода фиксации ОП и возможности 
раннего закрытия обширных ран и дефектов мягких тканей.

\section{Материалы и методы исследования}

В 2008 - 2016 гг. в Ортопедо-травматологическом центре Киевской областной клинической больницы проведено лечение 286 пациентов с ОП, в том числе 37 (12,94\%) - с ОП костей плеча, 70 (24,48\%) - предплечья, 44 (15,38\%) - бедра и 135 (47,20\%) - голени. Мы использовали классификацию ОП Густильо-Андерсена, за исключением пациентов, которым лечение в центре проведено в 2013 и 2014 гг, когда переходили от одних методических подходов к другим и ни одна из лечебных тактик не соблюдалась строго.

Согласно классификации Густильо-Андерсена ОП I степени были у 65 (22,72\%) больных, II - у 114 (39,86\%), III - у 107 (37,42\%). Средний возраст пациентов - (35 $\pm 7,5)$ года. Мужчин было 193 (67,48\%), женщин - 93 (32,52\%). Травмы вследствие дорожно-транспортных происшествий отмечены у 123 (43,01\%) пациентов, производственные - у 38 (13,29\%), бытовые - у 99 (34,62\%). У 26 (9,09\%) пациентов зафиксированы огнестрельные ранения верхних и нижних конечностей. Критериями исключения пациентов из исследования был возраст до 18 лет, а также лечение в Центре в 2013 и 2014 гг.

В 2008 - 2012 гг. подход к лечению пациентов с ОП был прост: первичная хирургическая обработка (ПХО), иногда выполненная в других больницах, стабилизация переломов аппаратами внешней фиксации (АВФ) и вторичная хирургическая обработка ран при возникновении осложнений. Дефекты мягких тканей закрывали с использованием свободной кожной пластики. Эпизодически с привлечением пластических хирургов ожогового отделения больницы выполняли пластику дефектов кожных покровов перекрестными лоскутами. Подобная тактика не была успешна, поэтому возникла необходимость изменения протоколов оказания помощи данным пациентам, и мы начали активно применять тактику многоэтапного хирургического лечения, которая заключалась в выполнении первичной и повторной хирургической обработки, первичной внешней и вторичной внутренней фиксации и этапном закрытии ран и дефектов мягких тканей. Пересмотр подхода был связан и со значительным потоком пациентов с огнестрельными повреждениями из зоны АТО. Данная тактика была распространена также на лечение остальных пострадавших с высокоэнергетическими травмами верхних и нижних конечностей.

Для изучения эффективности предложенных подходов все пациенты были разделены на две группы. В 1-ю группу вошли 204 пациента: 27 (13,24\%) - с ОП костей плеча, 45 (22,06\%) - предплечья, 40 (19,61\%) - бедра, 92 (45,09\%) - голени.

Первичная лечебная иммобилизация у 123 (60,29\%) пациентов проведена с использованием АВФ, у 52 (25,49\%) - пластин, у 11 (5,39\%) - интрамедуллярных стержней, у 18 (8,83\%) - других средств фиксации (гипсовой повязки, спонгиозных винтов, 8-образного проволочного серкляжа). Первичный внешний остеосинтез выполнен 123 (60,29\%) пациентам, в том числе 12 (9,76\%) - с ОП І степени, 48 (39,02\%) - II, 63 (51,22\%) -
III степени. Через 2 - 6 нед после первичного внешнего остеосинтеза и заживления раны у 63 (51,22\%) пациентов АВФ заменили на пластину, у 55 (44,72\%) - на интрамедуллярный стержень, у 5 (4,07\%) пациентов лечение продолжили без замены АВФ.

Первичный накостный остеосинтез выполнен 52 $(25,49 \%)$ больным с ОП I, II степени, в том числе 8 $(15,38 \%)$ - с ОП костей плеча, 11 (21,15\%) - предплечья, 15 (28,85\%) - бедра, 18 (34,62\%) - голени; первичный остеосинтез блокированным стержнем выполнен 11 (5,39\%) пациентам, в том числе 5 (45,45\%) - с ОП костей бедра, 6 (54,55\%) - голени.

Тактика лечения ран в 1-й группе зависела от их тяжести и наличия дефекта мягких тканей. При ОП І степени у 38 (18,63\%) пациентов выполнили ПХО или туалет раны; при ОП II, III степени у 103 (50,49\%) больных ПХО. Повторную хирургическую обработку применили у 63 (30,88\%) пациентов, что дало возможность осуществить ревизию раны с удалением некротических тканей и одновременно улучшить внешнюю фиксацию переломов.

После ПХО и стабилизации перелома АВФ 14 (6,86\%) пациентам с ОП ІІІ степени выполнены пластические операции. У 5 (35,71\%) пациентов с ОП ІІІА степени обширные дефекты мягких тканей в течение 1 - 2 нед закрывали искусственной кожей, а затем применяли аутодермопластику свободным расщепленным кожным лоскутом. У 4 (28,57\%) пациентов первично в течение 2 нед применяли вакуумную терапию, после уменьшения и очищения раны - пластику свободным расщепленным кожным лоскутом. У 5 (35,71\%) пациентов с дефектами мягких тканей выполнена пластика ротационным, суральным или паховым лоскутом.

Во 2-ю группу вошли 82 пациента: 10 (12,19\%) - с ОП костей плеча, 25 (30,49\%) - предплечья, 4 (4,88\%) - бедра, 43 (52,44\%) - голени. У 26 (31,71\%) пациентов отмечены огнестрельные переломы верхних и нижних конечностей, полученные в зоне АТО. Для стабилизации ОП во 2-й группе также применяли внешний, накостный и интрамедуллярный остеосинтез.

Первичную лечебную иммобилизацию у всех 82 (100\%) пациентов проводили с использованием АВФ: у $12(14,63 \%)$ - с ОП І степени, у 28 (34,15\%) - II, у 42 (51,22\%) - III степени.

У 36 (43,90\%) пациентов с ОП I, ІІ степени, из которых у 5 (13,88\%) были ОП костей плеча, у 19 (52,78\%) - предплечья, у 1 (2,78\%) - бедра, у 11 (30,56\%) - голени, в течение первых 7 - 10 сут одноэтапно выполнены демонтаж АВФ и остеосинтез отломков костей интрамедуллярным блокированным стержнем - у 5 (13,89\%) и пластиной у $31(86,11 \%)$.

У 31 (37,80\%) пациента срок стабилизации АВФ превысил 12 сут, им применили следующий алгоритм: с целью профилактики инфекции на первом этапе проведен демонтаж АВФ и наложена гипсовая повязка или система скелетного вытяжения для заживления ран от стержней, на втором этапе, через 14 и более сут, выполнен внутренний остеосинтез. У 2 (6,45\%) пациентов для фиксации перелома использовали интрамедуллярный блокированный стержень, у 29 (93,55\%) - пластину. Решение о замене метода фиксации принимали с учетом клини- 
ческих (первичное заживление ран, отсутствие некроза и признаков воспаления) и лабораторных показателей (количество лейкоцитов, СОЭ, уровни С-реактивного белка и интерлейкина-6).

У 15 (18,29\%) пациентов до окончания лечения оставался АВФ: у 12 (80\%) - стержневой, у 3 (20\%) - Илизарова), что связано с обширными дефектами мягких тканей и заживлением ран с воспалением и некрозом мягких тканей.

Тактика лечения пациентов 2-й группы включала ПХО ран, стабилизацию их АВФ, при необходимости - повторную хирургическую обработку в течение 24 - 72 ч.

В результате травмы или проведенной хирургической обработки у 44 (53,66\%) пациентов возникли дефекты кожных покровов. На первом этапе для закрытия раны применяли временные методы: использование искусственной кожи - у 3 (7,32\%), VAC-системы у 11 (26,83\%) пациентов. После этого окончательное закрытие ран выполняли в сроки от 1 до 2 нед. Для этого у 9 (21,95\%) пациентов использовали аутодермопластику расщепленным лоскутом, у 18 (43,9\%) - кожнофасциальные, у 3 (7,32\%) - свободные микрохирургические лоскуты.

В системе лечения ОП ПХО по-прежнему незаменима и является основным способом профилактики инфекционных осложнений. В последние годы все чаще рекомендуют применять повторную хирургическую обработку (Second-look) как планируемое повторное оперативное вмешательство, дающее возможность уменьшить число инфекционных осложнений. При сомнительной радикальности ПХО, подозрении на инфицирование раны выполнили повторную хирургическую обработку у 30,88\% больных, причем у 8,3\% больных ее выполняли неоднократно, пока рана не становилась чистой и не было противопоказаний к ее закрытию.

Условия для благоприятного заживления перелома и раны мягких тканей обеспечивает стабильная фиксация перелома. Для фиксации переломов применяли внешний, накостный и интрамедуллярный блокированный остеосинтез. Логика данной тактики такова: в первые 2 - 3 нед после травмы главным является закрытие раны мягких тканей, для чего необходима миниинвазивная фиксация перелома с помощью аппарата и при необходимости - повторная хирургическая обработка или пластика.

Сегодня специалисты при лечении ОП применяют тактику раннего закрытия раны - к концу 1-й нед после травмы, потому что оставление ее открытой более 72 ч увеличивает риск развития инфекции и дегидратации кости. Столь раннее закрытие дефектов мягких тканей не всегда возможно, так как во многих лечебных учреждениях нет пластических хирургов или травматологов, владеющих методами реконструкции мягких тканей. В состав хирургов Центра была введена ставка пластического хирурга. Кроме того, сотрудники Центра прошли подготовку по пластическому закрытию кожных дефектов на курсах и в клиниках за рубежом, что позволило выполнять подобные операции без привлечения пластических хирургов из других клиник.

После заживления раны мягких тканей главная цель лечения - заживление перелома с одновременным вос- становлением функции смежных с переломом суставов. Такую возможность дает накостный или внутрикостный стабильно-функциональный остеосинтез. При применении двух методов фиксации на первом этапе максимально используются достоинства АВФ как самого атравматичного метода, на втором - блокированного стержня или пластины, которые, стабильно фиксируя перелом, не препятствуют раннему восстановлению функции.

Причинами инфекции у всех пациентов были: тяжесть травмы мягких тканей, неполное иссечение плохо васкуляризированных тканей, неадекватный гемостаз и закрытие раны с натяжением.

Нарушение функции смежных с переломом суставов связано с длительностью лечения осложнений воспалительного характера, поздней заменой метода лечения, длительностью лечения с использованием АВФ.

Для закрытия обширных ран и дефектов мягких тканей также выполняли этапные операции: на первом этапе раны закрывали с помощью аппарата для создания в ране отрицательного давления (Vacuum Assisted Closure) на уровне 15,7 - 20,0 кПа (125 - 150 мм рт. ст.), затем выполняли пластику расщепленным свободным кожным лоскутом. Метод отрицательного давления основан на использовании контролируемого отрицательного давления для создания среды, способствующей заживлению ран. При использовании этого метода происходит эффективное совмещение краев раны, отеки уменьшаются, формируется грануляционная ткань и улучшается кровоснабжение, обеспечивается эвакуация раневого отделяемого и инфицированного материала.

После ПХО и стабилизации перелома с помощью АВФ 12 больных 1-й группы с ОП III степени были переведены в отделение пластической хирургии, где им выполнены реконструктивно-пластические операции.

\section{Результаты}

У 17 (8,33\%) пациентов 1-й группы возникло раннее нагноение в области перелома: у 8 (47,06\%) - после накостного остеосинтеза, у 7 (41,18\%) - после внешнего, у 2 (11,76\%) - после замены метода. У всех больных выполнены хирургические вмешательства для устранения очага инфекции с дальнейшей антибиотикотерапией с учетом данных посева отделяемого из операционной раны и сохранением внутреннего фиксатора. В результате проведенного лечения у 10 (58,82\%) пациентов воспалительный процесс купирован и достигнута консолидация перелома, у 7 (41,18\%) воспалительный процесс купировать не удалось. Остеомиелит развился у 13 (6,36\%) пациентов: у 4 (30,77\%) - после первичного интрамедуллярного остеосинтеза, у 5 (38,47\%) - после накостного, у 2 (15,38\%) - после внешнего, у 2 (15,38\%) после замены метода остеосинтеза. Замедленное сращение переломов отмечено у 21 (10,29\%) пациента, формирование ложного сустава - у 8 (3,92\%), контрактуры крупных суставов - у 23 (11,28\%) пациентов.

Развитие острого нагноения отмечено у 4 (4,88\%) пациентов 2-й группы: после интрамедуллярного остеосинтеза - у 1 (25\%), накостного - у 1 (25\%), внешнего - у 2 (50\%) пациентов, у 1 (25\%) из которых в последующем развился хронический остеомиелит. В результате про- 
веденного лечения у 3 (75\%) пациентов воспалительный процесс был ликвидирован, 1 (25\%) пациент, у которого имелись рентгенологические и клинические признаки хронического остеомиелита, продолжил лечение с АВФ АО. Ложные суставы диагностированы у 5 (6,1\%) пациентов (у 2 (40\%) - после остеосинтеза пластиной, у 3 (60\%) - интрамедуллярным блокированным стержнем), контрактуры крупных суставов - у 6 (7,32\%).

Результаты лечения пациентов обеих групп оценивали с помощью клинических и рентгенологических методов. Учитывали рентгенологическую картину сращения перелома, субъективные ощущения больного, наличие нарушений биомеханических показателей, степень восстановления работоспособности, наличие ограничений движений в смежных суставах, деформаций и укорочений. Для оценки использовали модифицированную 100-балльную шкалу анатомо-функциональных результатов лечения переломов длинных костей Neer-Grantham-Shelton. Изучены результаты лечения 186 пациентов 1-й группы через 12 - 36 мес после травмы. Хорошие результаты получены у 102 (54,84\%) больных, удовлетворительные - у 41 (22,04\%), неудовлетворительные - у 23 (12,37\%).

Изучены результаты лечения 71 пациента 2-й группы через 12 - 24 мес после травмы. Хорошие результаты отмечены у 57 (80,28\%) больных, удовлетворительные - у 9 (12,68\%), неудовлетворительные - у 5 (7,04\%).

\section{Обсуждение}

При выборе метода фиксации при ОП верхних и нижних конечностей должны учитываться оптимальные условия для заживления ран мягких тканей после стабильной фиксации сломанной кости. Также для остеосинтеза целесообразно применять минимальное количество металла и приоритет при хирургическом лечении отдавать миниинвазивному остеосинтезу. Предпочтительное применение одностороннего стержневого аппарата было обусловлено возможностью закрытой репозиции и стабильной миниинвазивной фиксации, простым, быстрым наложением и минимальной кровопотерей при операции. Стабилизация перелома АВФ не закрывает доступ к ране, не мешает выполнению повторной хирургической обработки и, при необходимости, пластики дефекта мягких тканей. Поэтому внешняя фиксация ОП является надежным миниинвазивным средством стабилизации, экономящим время и снижающим риск возникновения осложнений, однако спицы или стержни аппарата, проходящие через мышцы, препятствуют полному восстановлению первоначальной функции, в связи с чем после заживления ран мягких тканей АВФ целесообразно менять на пластину или интрамедуллярный блокированный стержень. Такую тактику первичного внешнего, вторичного внутреннего остеосинтеза считаем наиболее безопасной и эффективной.

С целью стабилизации отломков костей больным обеих групп в первые часы после госпитализации выполняли первичную или повторную хирургическую обработку и внешний остеосинтез. Миниинвазивная внешняя фиксация позволяла стабилизировать перелом без дополнительной травмы, создавала условия для гладко- го и быстрого заживления раны. После стабилизации общего состояния и заживления ран мягких тканей, по возможности, выполняли стабильно-функциональный внутрикостный или накостный остеосинтез, после которого с первых дней была возможность восстановления функции конечности.

Остеосинтез блокированным стержнем без рассверливания костномозгового канала с немедленным закрытием раны применяли при ОП I, реже - II степени, как правило, в первые 6 - 8 ч после травмы. Рассверливание костномозгового канала обеспечивает лучшую механическую стабильность фиксации, но нарушает интрамедуллярную сосудистую сеть. Также у пациентов применяли остеосинтез пластиной, которую размещали под жизнеспособными мягкими тканями. Применение современных пластин с угловой стабильностью или ограниченным контактом предпочтительнее, так как при этом не нарушается периостальная васкуляризация фрагментов. Применение пластины в качестве мостовидной у пациентов 1-й группы являлось наилучшим способом сохранения жизнеспособности кости. Причины осложнений накостного остеосинтеза в 1-й группе пациентов связаны главным образом с ошибочным выбором показаний, травматичным выполнением операции, неадекватным лечением травм мягких тканей.

При лечении внутрисуставных переломов приоритетным считали восстановление конгруэнтности суставных поверхностей, которое у большинства больных выполняли с применением открытого накостного остеосинтеза. Пластины остаются окончательным выбором для остеосинтеза ОП метафиза, а также при диафизарных переломах костей предплечья, где вследствие мягкотканного покрытия они относительно безопасны и никакой другой имплантат не может обеспечить стабильность, необходимую для сохранения анатомической репозиции и связи между лучевой и локтевой костями.

Сравнительно успешное лечение ОП связано с выполнением многоэтапных операций. Рана при ее этапных обработках с последующим пластическим закрытием заживает практически без инфекционных осложнений.

При ОП дефекты мягких тканей, требующие реконструкции, были у 28,05\% пациентов 2-й группы. Лечение таких пациентов было длительным, требовало междисциплинарного сотрудничества специалистов и улучшения подготовки травматологов по вопросам пластики обширных ран и дефектов мягких тканей.

\section{Выводы}

1. Успех лечения ОП зависит от ранней госпитализации, ранней радикальной хирургической обработки, стабильной фиксации перелома, применения рациональных доз антибиотиков, коррекции иммунологического статуса. Одними из наиболее спорных и нерешенных являются проблемы выбора метода фиксации ОП и раннего закрытия раны.

2. Выбор метода стабилизации перелома зависит от тяжести общего состояния пациента, тяжести повреждений мягких тканей и сложности перелома. При ОП I степени для стабилизации перелома рекомендуется вы- 
полнять накостный или интрамедуллярный остеосинтез. При ОП II, III степени целесообразна тактика этапного хирургического лечения, которая заключается в выполнении первичной и повторной хирургической обработки, первичной внешней и вторичной внутренней фиксации, этапном закрытии ран и дефектов мягких тканей.

3. При ОП дефекты мягких тканей возникают у 35\% больных. Исходя из того, что пластические хирурги имеются не в каждом лечебном учреждении, целесообразно обучение травматологов не только стратегии и технике лечения переломов, но и методам восстановления дефектов мягких тканей.

\section{References}

1. Ruedi T, Murphy W, Colton C. AO Prinzihles of Fracture Management Thieme. Stuttgart; 2000:1-864.

2. Shibaev E, Ivanov P, Vlasov A, Kisel' D, Lazarev M, Nevedrov A, et al. Vosstanovlenie pokrovnyh tkanej u postradavshih s tjazhelymi otkrytymi perelomami kostej goleni. Zhurnal im. N. V. Sklifosovskogo «Neotlozhnaja medicinskaja pomoshh'». 2016;4(1):30-6. [In Russian].

3. Gustilo R, Anderson J. Prevention of infection in the treatment of one thousand and twenty-five open fractures of long bones: retrospective and prospective analyses. JBJS.1976;58(4):453-8.

4. Wirth C, Mutschler W, Kohn D, Pohlemann T. Praxis der Orthopädie und Unfallchirurgie. Georg ThiemeVerlag. 2013:1-1139. 